\title{
Ecology mediatization: strategy of biological resource management (on the example of the RNO-Alania)
}

\author{
Sergey Golovko ${ }^{1, *}$, Liudmila Kokhanova ${ }^{2}$, Tatiana Alekseeva ${ }^{2}$, Yulia Chereshneva ${ }^{2}$, and \\ Maria Gubanova ${ }^{3}$ \\ ${ }^{1}$ Russian State University for Humanities, 125047, Miusskaya Sq., 6, Moscow, Russia \\ ${ }^{2}$ Lomonosov Moscow State University, 125009, Mokhovaya St., 9, Moscow, Russia \\ ${ }^{3}$ Russian Presidential Academy of National Economy and Public Administration, 119571, Vernadsky \\ Prospect, 82, Moscow, Russia
}

\begin{abstract}
The article shows how the process of the formation of environmental mediatization concept contributes to the implementation of the bioresource management strategy. The research has been conducted in the subject of the Russian Federation, the Republic of North OssetiaAlania. This region has been selected as rather complicated and environmentally vulnerable due to the fact that natural resource and ethnocultural potentials pose severe challenges there. The final sample consists of 150 publications of an informational and analytical character published in the periodicals of the Republic of North Ossetia-Alania from 2017 to September 2021. These days, network information resources are considered the most effective tool of mediatizing ecology and developing a strategy for managing biological resources. However, as a result of the spontaneous approach to the formation of the RNO-Alania as an environmentally pristine region, there is an imbalance of both information coverage and coverage of environmental issues in comparison to other topics. The conducted research has made it possible to outline the parameters of the spontaneously developing network media system and highlight their main characteristics. Thus, the media image of the RNOAlania as an environmentally friendly region nowadays basically does not meet the requirements and challenges of modern times.
\end{abstract}

\section{Introduction}

Environmental component is an integral part of mediatization processes which, in their turn, characterize the life of contemporary society and all its social institutions. Academician N. N. Moiseyev claims that "mankind is challenged with the necessity of reconsidering the most profound bases of their world outlook, identifying their niche in nature, their interaction with the environment, reconsidering their civilization paradigm [9].

In order to as soon as possible realize the significance of the place of a human being in nature and the results of their activities, it is relevant to create a highly-developed and

* Corresponding author: Sgolovko@inbox.ru 
easily accessible strategy of biological resource management. This is what the majority of environmental programs emerging in the region are aimed at. They set the rational usage of natural resources as their paramount goal. One of the examples of these is the governmental project "Environmental Protection, Ecological Security, and the Welfare of the Republic of North Ossetia-Alania" in 2020-2025 (as amended on November, 26, 2019). The program was approved and adopted in the Republic of North Ossetia-Alania [5].

Practice shows that the prospect of strategy realization stated in the program largely hinges on how thoroughly the information on the republic's environmental state will be presented in the public sphere, and to a huge extent, in network media space. These days, the Internet in various formats plays the key role in forming the informationcommunicational system of the country. Hence, the impact of the Internet on every citizen and various forms of their activities and society in general is undeniably on the increase.

The goal of this particular research is to show how the emergence of the concept of environment mediatization by network information resources promotes the realization and implementation of biological resource management strategy. The RNO-Alania has been selected as an example because of its complexity and environmental vulnerability. It is the region where "the natural resource and ethno-cultural potentials obviously tend to decrease and decline. An enormous number of conflicts only deteriorate the current situation." [8].

Nevertheless, the RNO-Alania participates in 50 out of 67 federal projects that comprise national projects including the national project "Ecology". The republic came third on the list of the amount of financing in 2019 in the Russian Federation. This fact indicates that the region is in the process of developing the strategy of its biological resource management, which contributes to environment mediatization as an indispensable part of social life.

The set goal consists in resolving a few tasks:

to outline the parameters of spontaneously forming system of network media covering environmental issues;

to determine the key topic areas;

to characterize the theme of ecology as one of the basic components of forming media image of the RNO-Alania as the region which develops and implements the biological resource management strategy.

\section{Materials and research methods}

The study of environment mediatization in the process of implementing the bioresource management strategy in media space of the RNO-Alania is based on the principles of comparative analysis of complex scientific methodology, historical-cultural analysis, and interdisciplinary approach. The basic ideas of the principle of mediatization were laid in the works of M. McLuhan [7]. In recent years, these ideas have been developed in the research papers of the representatives of various scientific schools. The analysis of special literature on the selected topic has revealed that researchers are mostly interested in the mediatization of such social institutions as the government, law, culture, and religion. Environment mediatization is paid less attention to. Moreover, environmental and ecological information mostly bears a certain amount of negative connotation, which causes tension in society.

Both, journalistic and natural-scientific papers have proved really helpful in the process of developing the methodology of the research below. Above all, these are the papers studying the media facilities and opportunities in creating a media image [6]. Besides the abovementioned works, these are the ones that define the specificity of the mountainous territories of the RNO-Alania, which enables structuring information themes as the method of rational nature management and nature protection activities. These papers include the works of D. V. Abbasov [1], D. V. Bubnov [3], Kh. Kh. Makoyev [8], I. K. Gerter and V. 
S. Misakov [4], L. Sh. Akhmedova and G. I. Idziyev [2], N. F. Reimers [10], I. Khuzmiev [13] and others.

The selection of this region by the authors of this paper has not been made randomly. First of all, it is due to the fact that we live in the country where, according to the statistics presented by G. S. Samoylova, "out of 89 subjects of the Federation, 43 have mountains. The area of these regions amounts to $85,5 \%$ of the total area of the Russian Federation, in which mountains form $63 \%$ of the area, i.e. mountains make $53,6 \%$ of the territory of Russia." [11]. Secondly, Kh. Kh. Makoyev claims that "The Northern Caucasus is the only region in the European part of Russia which maximally meets all the classic criteria and standards of mountainous countries: in altitude and disjunction of landform, landscapeclimatic and ethno-cultural diversity, and household and settlement peculiarities." [8].

At present, there take place such processes as rapid development of informationcommunication technologies, transformation of conventional mass media and creation of their hybrid forms, such as media with online versions as a must-have and evolution of social networks, which consequently leads to a spontaneously forming system of network media or information resources. Ever-increasing amounts of information and audience segmentation are among the characteristic features of this system [12].

The following empirical methods have been applied in the research paper: media space monitoring, online observation, structural and visual analysis of network media and their content, expert survey. Methods of random sample have been employed in selecting the empirical material. The base of media texts has been formed to include the name of the RNO-Alania as the subject of the RF mentioned together with the keyword "ecology" in headlines and abstracts. From this media text base there have been selected 15 network information resources later united into 5 structural media groups:

- online versions of conventional periodicals;

- network periodicals;

- $\quad$ specialized scientific resources;

- $\quad$ information resources including official websites of events;

- websites of organizations and state institutions.

The first group includes both federal periodicals ("Rossiiskaya Gazeta", "Kommersant", etc.) and local mass media (the republican newspaper "Severnaya Ossetia", television and radio of the RNO-Alania, and others). The final sample is presented by 150 information and analytical articles published in these periodicals from 2017 to September 2021.

\section{Research results}

The article below partly presents the results of the research based on the analysis of the information-communication space of the RNO-Alania and the trends stipulating its evolution. A number of tasks have been formulated and accomplished during the study. First of all, the primary condition for environment information to be considered as the method of rational nature management is its presence in the region's informationcommunication space. In this particular case, it has been determined that there is such information in the RNO-Alania's informational sphere.

The second, no less important, is the condition of structuring informationcommunication space in which environmental information functions. In the republic it includes such traditional segments as print media, radio, and television. During the past few decades this condition has changed dramatically due to the emergence of online versions of conventional mass media. Thus, the republic's daily newspaper "Severnaya Ossetia" comes out not only in the paper version, but also has its website (http://sevosetia.ru/Article/Index/229994). On this platform it is possible to see the paper's previous issues and how often it covers environmental topics. Among such articles the 
following can be mentioned: "Awards to Environmental Activists" (07.12.2018), "How Do We Respond to Environmental Challenges?" (07.02.2019) by S. Suanov, and others. It is noteworthy that the correspondent of "Severnaya Ossetia" has been awarded the first prize for the best article on this topic in print media. This environmental contest has been held by the North Ossetia Republican Department of the All-Russian Environmental Protection Society.

Let us give a little example of the article published in "Severnaya Ossetia" on the environmental issues (section "Society". The question of the day. 08.09.2021).

How do you estimate the state of environment in the region?

Murat KUCHIYEV, student of GSAU (Gorsky State Agrarian University), Kosta Village, Ardon Disrtict:

- I believe that in our republic it is enough to spend some time on the bank of any river to understand that nature needs protection: protection from people who by using all the beauty of their local nature shamelessly destroy it. You may ask, "How?" - by piles of rubbish that they do not only leave after an outing near the river, but also throw into the water. Lots of times I've seen bottles, watermelon rind, and plastic bags full of dirty disposable dishes. I feel ashamed of people like these, and the state of our rivers makes me feel depressed. Not only rivers, by the way. The same scenes can be witnessed in the mountains, and in this case I feel ashamed of the tourists who see our beautiful nature and our attitude to it.

Yulia AKSYONOVA, the resident of Mozdok who cares, environmental activist:

- Unfortunately, we are insufficiently informed by competent authorities about the environmental situation in the republic to be able to evaluate it. High sickness rate is one of the attributes of poor state of the environment.

Alexandra RADCHINSKAYA, student of North Ossetia State Institute of Pedagogy:

- Of course, in comparison to major regions of Russia the state of environment in North Ossetia is more or less favorable. But this fact cannot serve as a consolation. We lack in modern education in the sphere of ecology, our mountain rivers - the pride of the republic will soon become plastic, a dustbin or rubbish container is still scarce in many of our streets. And this list of problems is far from being complete. I think we ought to be ashamed of violating the simplest environmental rules.

Valentin KISIYEV, a veterinary:

- I consider the state of environment in our republic satisfactory. At present there are no big factories which could contribute to air and atmosphere pollution. Moreover, factories producing alcoholic beverages are practically non-functional. So, there is no one to dump distiller's grains into the rivers.

At the same time, the issue of recultivating the territory near the former plant "ElectroZinc" still remains really acute, and it will probably take long to solve it. Other areas of concern include automobiles which emit harmful poisonous substances into the atmosphere and some people who litter where they like.

Yu. SLANOVA, journalist:

- I've recently noticed that dustbins have been removed from many public transport stops. As far as I understand, they are supposed to be replaced by new ones, but their absence makes people drop litter on the ground. I would also like to touch upon the issue of big rubbish containers installed throughout the city. They are frequently overfilled, rubbish falls out of them, and the smell spreads all over the street. The issue of smart rubbish recycling and utilization deserves immediate attention. Despite the fact that special containers are installed throughout the city and in NOSU (North Ossetia State University) as well, not everyone takes the trouble of sorting rubbish out.

Network space is also used by Ossetia's radio and television that have their electronic addresses (http://alaniatv.ru), which enables interpreting their category characteristic of 
connection with the time and place in a somewhat different way. Now watching a particular program on TV or listening to it on the radio is possible on the Internet depending on an individual's wishes and preferences. Thus, for instance, the news about the "children of North Ossetia who contributed to environmental protection by their drawings" posted on the Internet at 17.38. on November, 23, 2018, can be accessed at any time convenient for every person.

It goes without saying that the functioning of such resources as "Vladikavkaz Region Online" (news-r.ru), North Ossetia-Alania News (https://newsr.ru/news/north_ossetia_alania/), Region 15 (https://region15.ru/); electronic network periodical "Vercherniy Kurier" (https://vk-smi.ru/); "Kavkazsky Uzel" (https://www.kavkaz-uzel.eu/), and others make information on environmental issues more open and accessible to residents of the region. To some extent, they work to foresee events by informing about topical ecological issues before this news is published in a newspaper or broadcast on TV.

The research paper below has once again confirmed the fact that the Internet is a living creature. As it can be inferred from the network space analysis of the RNO-Alania, currently there are about one hundred information resources in the region which, to a certain extent, deal with the issues of nature management in the republic. Some of these resources are locally based, some operate outside the region. Environmental news of the republic is covered far less frequently by federal information resources.

At the same time, not only press but regional local authorities realize the crucial role of new channels of disseminating information and are gradually starting to use them in their work. Moreover, sometimes periodicals lose to them in terms of the speed of posting on the Internet. Among them it is necessary to mention both servers of state institutions and websites of public organizations. The information-communication space is represented by the official site of the RNO-Alania (http://alania.gov.ru), the Parliament of the RNO-Alania (http://parliament-osetia.ru), and other governmental bodies and institutions. Practically all the ministries and departments of the republic are represented on the Internet by their press offices. Websites of the Ministry of Interior of the RNO-Alania (https://15.мвд.pф) and press office of the Ministry of Environment of the RNO-Alania (http://mpr.alania.gov.ru), Federal State Department "Central Water Resources" of the RNO-Alania (http://fgualania.ru), and others give a wide coverage of topics related to the environment.

The fact of using the information of press offices by other information resources proves the statement that managing by means of information as a method is quite efficient. For example, the website "Ossetia-Iryston" publishes the article headlined "Commission on Investigating Cause of Fire at JSC "Electro-Zink" Plans to Complete Work on December, 20". Further on it continues: "If only the results of expert examination of the police and the Ministry of Emergency Situations are ready by this time, according to the press office of the government of the RNO-Alania." (07.12.18 at 17:54).

"Region 15 (North Ossetia)" provides information with reference to information sources - press offices of various departments. For instance, it reports: "Power engineers of North Ossetia have given an eco-class within the all-Russian project "Nature Concerns Children". Press office of the subsidiary of JSC IDNC NC (Interregional Distribution Network Company of the North Caucasus) - "Sevkavkazenergo" (21.04.2017 at 14:51).

One more example of articles published by "Region 15 (North Ossetia)": "At "The Forum of Action" the activists of PNF (the Public National Front) of North Ossetia have mentioned the problem of worn-out water pipes in the region. Press office of PNF of the RNO-Alania." (19.12.2017 at 10:29).

It is worth mentioning that due to the Internet, the information-communication space of the RNO-Alania is dynamically developing, thus expanding its opportunities of information management in the sphere of environmental usage and protection. Today, there are 
permanently renewed sites, portals, blogger communities on social networks and other new platforms such as Telegram messenger or YouTube. So, "Region Vladikavkaz Online" has its own telegram channel where it posts "topical news interesting for everyone" (https://tele.click/news_r_vladikavkaz). On YouTube the following videos can be found: "Discussing Environmental Protection Issues" (https://youtube.com, 25.10.2016), "Open Dialogue: "Electro-Zinc" Plant, the RNO-Alania (https://youtube.com, 25.10.2018), "In the Ministry of Natural Resources and Ecology of the RNO-Alania" (https://youtube.com, 25.10. 2019).

The official page of the Ministry of Interior of the RNO-Alania on the "Instagram" is two years old. The republic has created its own network "My Caucasus" as the social net of the Caucasus (MyKavkaz) where photos, videos, and blogs are posted and regional forums are stated.

At the same time, the spontaneously forming system of network media possesses, in the authors' opinion, the following peculiarities:

- uneven coverage saturation;

- wave-like frequency;

- prevalence of information genres;

- low emotiveness of media texts;

- communication strategy deficiency;

- explicit nature of publications.

Let us take a more thorough look at all of the above mentioned characteristics.

Uneven coverage saturation. System saturation is determined by the permanence of parameters conditioned by the equality of speed of opposite processes taking place simultaneously.

The survey results have revealed utter irregularity of information product coverage in different regions of the RNO-Alania (Table 1).

Table 1. Saturation with information product.

\begin{tabular}{|l|l|l|}
\hline No. & Region & $\begin{array}{l}\text { Number } \\
\text { publications }\end{array}$ \\
\hline 1 & Vladikavkaz & 119 \\
\hline 2 & Alagir District & 3 \\
\hline 3 & Ardon District & 7 \\
\hline 4 & Digor District & 1 \\
\hline 5 & Iraf District & 3 \\
\hline 6 & Mozdok District & 7 \\
\hline 7 & Kirov District & 1 \\
\hline 8 & Pravoberezhny District & 6 \\
\hline 9 & Prigorodny District & 3 \\
\hline Total: & & 150 \\
\hline
\end{tabular}

Wave-like frequency. The number of publications increases in a wave-like manner to react to the new decrees of the President and the government and gradually decreases shortly after another political event is over.

Low emotiveness of media texts. Ecological issues coverage in contemporary mass media is distinguished by an emotionally neutral character. Transmitting aggressively colored news makes a huge impact on the audience, and thus enables interpreting events by manipulating public perception and imposing positive or negative attitudes to the audience.

However, these days, evaluative vocabulary and stylistic devices of all kinds have given way to dry balanced coverage of events and facts. Thus, in most articles on environmental issues studied with the application of content-analysis methods emotional expressive vocabulary (either positive or negative) was not found. 
Prevalence of information genres. Genre diversity of contemporary environmental discourse is extremely scarce. The overwhelming majority of publications are presented in the genre of informational notes (no more than 500 words) characterized by dry unemotional narration. Analytical interview has given way to an information one. Lack of analytical materials may account for the authors' unwillingness to seriously tackle the problem of resolving the region's challenging environmental issues.

Communication strategy deficiency. If the discourse of federal periodicals is basically formed by the current governmental policy of the region and aims at the maximal audience scope, the topics of local media are, as a rule, narrow and are not intended for large groups of readers.

Staff reporters "on the spot" do not usually associate their activities with the news about this particular community and local journalists deeply absorbed in reality are unable to "raise and develop the issue" due to the narrowness of editorial policy.

Internet periodicals, especially federal news agencies (TASS, RIA "Novosti", Russia Today, etc.), can be referred to as a powerful information resource with a vast network of news bureaus, technologies, and sources of information. But loose, scattered structure of thematic presentations hinders the formation of any real viable structures.

The same refers to the specialized scientific resources which, unlike news agencies, possess a deeper approach to understanding themes. In this particular case, the depth of analyzing together with thematic narrowness does not create the synergetic effect of communicative influence and, consequently, the effect of a complete media image.

Explicit nature of publications. Absence of the rigid "agenda" cannot contribute to the creation of a full information picture of the region's environmental problems: that is why the majority of materials which form the information discourse core are explicit and nonconceptual in character.

\section{Conclusions}

Nowadays, network information resources are considered as the most efficient tool of ecology mediatization and biological resource management strategy development. However, as a result of a spontaneous approach of network information resources to forming the image of the RNO-Alania as a pristine area, there arises imbalance of both information coverage and environmental issues coverage in comparison to other topics.

The conducted research has enabled outlining the parameters of the spontaneously forming system of network media and defining their basic characteristics: uneven coverage saturation; wave-like frequency; prevalence of information genres; low emotiveness of media texts; communication strategy deficiency; and the explicit nature of publications.

Media activities are not coordinated, information strategies are more declared rather than implemented in practice. The process of shaping the media image of a unique republic by means of network resources is rather spontaneous guided mostly by momentary interests of a particular editorial management.

According to statistics, environmental topics are termed as of paramount significance in the State Program "Environmental Protection, Ecological Security, and the Welfare of the Republic of North Ossetia-Alania in 2020-2025 (as amended on November, 26, 2019)" which is adopted in the Republic of North Ossetia-Alania [5]. However, this program has so far not been fully understood by those who are supposed to implement it.

The conducted analysis of articles devoted to environmental issues has revealed a rather one-sided prejudiced approach to forming the thematic core of media texts. So, most of the publications are created in the genre of information note, there is lack of analytical materials, and not all the trends of social policy are given prominence to. The scarcity of 
analytical articles may account for the authors' unwillingness to seriously tackle the problem of resolving complicated environmental issues.

Thus, the media image of the RNO-Alania as an ecologically pristine area created by the network information resources does not fully meet modern challenges and requirements of the present day.

\section{References}

1. D. V. Abbasov, Terra Economicus, 12, 202 (2014)

2. L. Sh. Akhmedova, G. I. Idziyev, Regional Economy: Theory and Practice, 18,12 (2013)

3. D. V. Bubnov, Thes. for Ph.D. in Economics, Volgograd SU (2014)

4. I. K. Gerter, V. S. Misakov, Terra Economicus, 10, 123 (2012)

5. State Program of the Republic of North Ossetia-Alania "Environmental Protection, Environmental Security, and the Welfare of the Republic of North Ossetia-Alania" in 2020-2025 (as amended on 19.12.2017), https://docs.cntd.ru/.

6. M. V. Gribok, INTERCARTO. INTERGIS. 26, 94 (2020)

7. M. McLuhan, Hyperborea. Kuchkovo Field (2007)

8. Kh. Kh. Makoyev, Izvestiya TulSU: Theor.Sciences, 2, 234 (2009)

9. N. N. Moiseyev, MGVP COX (1995)

10. N. F. Reimers, Mysl (1990)

11. G. S. Samoylova, Izv. RAN. Series: Geography, 2, 110 (1999)

12. A.V. Chizhik, Communicology, 5, 55 (2017)

13. I. Khuzmiev, https://helpiks.org/ 